\title{
Relative Concerns about the Uprising Level Of smog In the Capital Area of Lahore
}

\author{
Asma Aleem ${ }^{\mathrm{a}}$, Maria Idrees $^{\mathrm{b}}$, Tangina Malik $^{\mathrm{c}}$, Asiya Saif $^{\mathrm{d}}$, Arslan Saeed $^{\mathrm{e}}$. \\ a asmaaleem26@gmail.com, ${ }^{b}$ mariaidrees189@gmail.com, ${ }^{c}$ tanginamalik@ rocketmail.com, ${ }^{d}$ asiya.smile99@gmail.com \\ ,'arzlansaeed@gmail.com \\ ${ }^{a}$ Senior Lecturer, School Of Physical therapy, JIPS/johar institute of professional studies, Lahore 54000 Pakistan; ${ }^{b}$ Lecturer, School Of \\ Physical therapy, JIPS/johar institute of professional studies, Lahore 54000 Pakistan; ${ }^{C}$ Lecturer School of pharmaceutical Sciences, \\ JIPS/johar institute of professional,Lahore 54000 Pakistan, ${ }^{d}$ Lecturer School of pharmaceutical Sciences, JIPS/johar institute of \\ professional, Lahore54000 Pakistan; ${ }^{e}$ Lecturer School of physical therapy, JIPS/johar institute of professional, Lahore 54000 Pakistan.
}

Published by IJRP.ORG. Selection and/or peer-review under responsibility of International Journal of Research Publications (IJRP.ORG)

Keywords: Smog;Asthma

Pakistan is the most urbanized nation in South Asia (Ali, M et al.) and its second-biggest city Lahore, developing at a rate of $4 \%$ annually, is viewed as the most polluted city in Pakistan. Developed cities are potently afflicted by smog in Asia, and Lahore is no reservation. Following the example of a year ago, Lahore has once again been immersed by a shockingly substantial cover of smog, covering the whole city and negatively affecting individuals' lives. The excessive ascent in cars, unchecked deforestation, speedy urbanization, and unremitting development of industries (Sanchez-Triana, E et al.) have led to this panic condition throughout the long term.

Lahore city faced spells of smog throughout the most recent couple of years which has not only caused well-being issues as well as caused various road traffic accidents because of poor deceivability (The News, 2016). These issues incorporate irritation in eyes, breathing problems; cough and wheezing exaggerate asthma attacks. An examination discloses that air contamination enhances persistently obstructive pulmonary lung disease (Paulin, L.M et al.)Television and web was favored over data from customary sources like papers, books and expert lectures. They offer a vast knowledge with ease and accessibility. 
Manifestation to smog can cause cough, pulmonary tract irritation, prompting and intensifying of asthmatic attack and damage of lung. Face mask don't give sufficient securities against the smog (Wang, Y et al.). A few perception stations and media detailed the ground-based perceptions of air contamination diminished during the public lockdown time frame everywhere in the world (Mahato,S et al.).

\section{Conclusion}

Most of respondents were disappointed with the air quality in Lahore. Expected disintegration of air quality in future and its consequences for wellbeing had constrained the respondents to take defensive estimates, for example, diminished outside exercise, scaling back end of the week travel and decreased window opening time; in any case, a minority utilized face covers. Public briefing is additionally significant through media, as anticipation from smog exposure is ideal to drop off this from the out growth. People ought to be instructed to receive every preventive measure. Courses, media, press and public awareness walks will be useful. Long term anticipation could be overcome through plantation, high stacks; evasion of harvest consuming and gas-controlled motors for vehicles ought to be utilized.

\section{Acknowledgements}

I would like to express my special thanks of gratitude to my colleagues who helped me and guided me to make such a project. I had made this project from my heart and show utmost sincerity to complete it. It helped me increase my knowledge and skills.

\section{References}

Ali, M. and Athar, M., 2010. Impact of transport and industrial emissions on the ambient air quality of Lahore City, Pakistan. Environmental monitoring and assessment, 171(1-4), pp.353-363.

Sanchez-Triana, E., Enriquez, S., Afzal, J., Nakagawa, A. and Khan, A.S., 2014. Cleaning Pakistan's air: policy options to address the cost of outdoor air pollution. The World Bank.

Paulin, L.M., Gassett, A.J., Alexis, N.E., Kirwa, K., Kanner, R.E., Peters, S., Krishnan, J.A., Paine, R., Dransfield, M., Woodruff, P.G. and Cooper, C.B., 2020. Association of long-term ambient ozone exposure with respiratory morbidity in smokers. JAMA internal medicine, 180(1), pp.106-115.

Wang, Y., Sun, M., Yang, X. and Yuan, X., 2016. Public awareness and willingness to pay for tackling smog pollution in China: a case study. Journal of Cleaner Production, 112, pp.1627-1634.

Mahato, S., Pal, S. and Ghosh, K.G., 2020. Effect of lockdown amid COVID-19 pandemic on air quality of the megacity Delhi, India. Science of the Total Environment, p.139086. 